\title{
Quantification of TOC and TN in reservoir sediments using Fourier transform infrared spectroscopy
}

\author{
Lin Mei ${ }^{1}$, Yihong Yue ${ }^{1}$, Yong Qin ${ }^{2}$, Xueping Chen ${ }^{1}$, Fushun Wang ${ }^{1,}$ \\ 1 School of Environmental and Chemical Engineering, Shanghai University, Shanghai 200444, China \\ 2 College of Food Sciences, Xinyang Agriculture and Forestry University, Xinyang 464000, China
}

H I G H L I G H T S

- A calibration models for the rapid determination of TOC and TN contents using FTIRS.

- A rapid analytical method for quantitatively calculating TOC and TN.

- A general model for TOC and TN quantitative analysis in reservoir sediments in the southwest China.

\section{ARTICLE INFO}

Article history:

Received July 20, 2021

Revised August 28, 2021

Accepted September 2, 2021

Keywords:

Fourier transform infrared spectroscopy

Chemometrics

Total organic carbon

Total nitrogen

Reservoir sediment
GRAPHICAL ABSTRACT

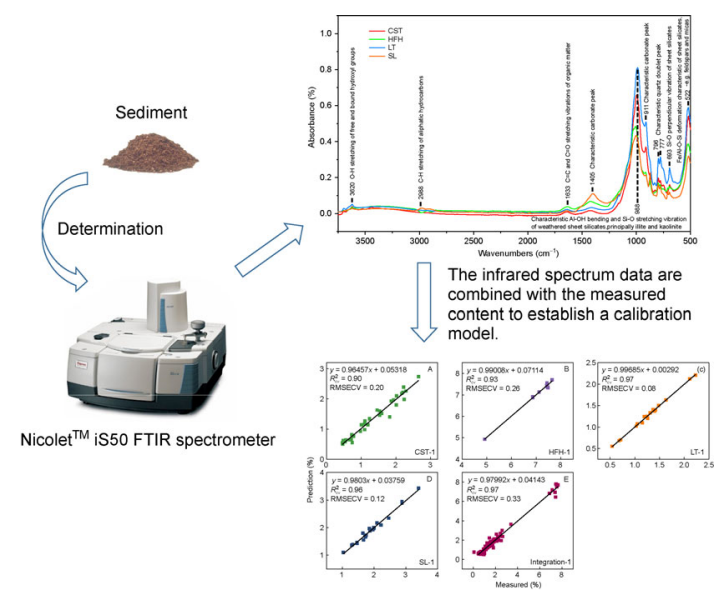

A B STR A C T

This study aims to quantitatively assess the total organic carbon (TOC) and total nitrogen (TN) content of reservoir sediments in southwest China using Fourier transform infrared spectroscopy (FTIRS). FTIRS measurements were performed on 187 sediment samples from four reservoirs to develop calibration models that relate FTIR spectral information with conventional property concentrations using partial least squares regression (PLSR). Robust calibration models were established for TOC and TN content. The external validation of these models yielded a significant correlation between FTIR-inferred and conventionally measured concentrations of $R^{2}=0.88$ for TOC, $R^{2}=0.90$ for TN. This method can be performed with a small sample size and is nondestructive throughout the simple measurement process. The TOC and TN content in the sediment can be determined with high effectiveness without being overly expensive, making it an advantageous method when measuring a large number of samples.

(C) Higher Education Press 2021
* Corresponding author

E-mail address: fswang@shu.edu.cn (F. Wang)

\section{Introduction}

Lakes and oceans usually contain large amounts of sediment, which record information about past environmental and climate changes (Liu et al., 2013). These sediments contain copious amounts of geochemical information, such as the 
total organic carbon (TOC), total nitrogen (TN), and biogenic silica. For example, the famous sediments of Lake Baikal (Peck et al., 1994; Colman et al., 1995; Williams et al., 1997), Lake Tanganyika (Cohen et al., 1993), Lake Malawi (Tiercelin and Lezzar, 2004), Lake Biwa (Fuji, 1998), and other have recorded over a million years of environmental information. Extracting information from these sediments requires complex analytical procedures and various scientific instruments, making the process both time-consuming and expensive. The traditional method to determine the TOC and TN content requires an element analyzer, but the sophisticated pretreatment process drastically lowers efficiency when measuring a large number of samples.

Fourier transform infrared spectroscopy (FTIRS) is widely used in material analysis as a physical characterization technique (Allen et al., 1994; Coury and Dillner, 2008). The basic principles of FTIRS involves using infrared radiation to stimulate molecular vibrations, which is absorbed at specific energy levels depending on the material composition as the result of quantum mechanics. Most compounds demonstrate the characteristic infrared spectra, which can be used to determine its organic and inorganic composition, including carbohydrates, fatty acids, humus material, silicate and carbonate compounds. The absorbance of the FTIR spectrum directly relates to the concentration of specific sediment components, thus organic and mineral components can be quantified using FTIRS. Due to this, FTIRS has been applied to the study of marine and lake sediments, such as in the quantitative prediction of TOC (Rosén and Persson, 2006), TN (Vogel et al., 2008), BSi (Sifeddine, 1994; Bertaux et al., 1996; Wirrmann et al., 2001), carbonate (Mecozzi et al., 2001), and humus contents (Braguglia et al., 1995; Belzile et al., 1997; Calace et al., 2006) in lake and marine sediments. These studies used a site-specific or region-specific calibration model to quantify the selected components. However, it is still uncertain whether a more universally applicable FTIRS calibration model can be developed and utilized for artificial reservoirs due to its evidently different environment. Artificial reservoir sediments differ from marine and lake sediments in many aspects, such as material composition and sedimentation rate. The main sources of reservoir sediments are aquatic and terrestrial plants, sediment from upstream water sources, and the external environment. Therefore, it is necessary to incorporate chemometric analysis when investigating geochemical properties using FTIRS to explore its ability to extract geochemical information from highly heterogeneous reservoir sediments in the practical field. This study combined a large number of samples from four reservoirs located in south-west China to develop a universally applicable FTIRS calibration model for the rapid quantification of TOC and TN. The primary purpose of this study is (1) to establish a calibration model by combining TOC and TN contents measured by traditional methods with FTIRS spectral data, (2) to evaluate the prediction performance of the model, and (3) to establish a calibration model for both single and integrated reservoirs.

\section{Materials and methods}

\subsection{Sample collection}

In this study, four reservoirs located in the region of southwest China were investigated, specifically the Chaishitan (CST), Hongfenghu (HFH), Longtan (LT), and Silin (SL) reservoirs (Fig. 1). This region is part of the subtropical monsoon climate zone, which is affected by the mid-latitude and low-latitude tropical weather system and is humid, hot and rainy. In each reservoir, two sediment cores were collected using a gravity sediment core sampler (labeled as SL-1 and -2, HFH-1 and -2 , CST-1 and -2 , and LT-1 and -2 , respectively). These sediment cores were cut at $1 \mathrm{~cm}$ intervals, placed in sealed bags, and brought back to the laboratory for freezing and storage.

\subsection{Traditional analysis}

Prior to analysis, the sediment samples were freeze-dried and ground into 80 -mesh fine powder form. A total of $2 \mathrm{M} \mathrm{of} \mathrm{HCl}$ was added to remove inorganic carbon from the sediment samples, which were then repeatedly washed with deionized water for neutralization and re-dried for measurements. The TOC and TN content of the pre-treated sediment samples were determined using an elemental analyzer (Thermo Fisher Scientific Flash 2000 HT).

\subsection{FTIRS analysis}

For FTIR analysis, the sediment samples were simply freezedried and ground to $80-$ mesh. The Nicolet ${ }^{\mathrm{TM}}$ iS50 FTIR spectrometer produced by Thermo Fisher Scientific was used and equipped with an integrated mid-infrared and far-infrared diamond ATR module. It is also more time consuming since there is no need to press tablets. An approximate $50 \mathrm{mg}$ sample was scanned 32 times at a $4 \mathrm{~cm}^{-1}$ resolution between the range of $400 \mathrm{~cm}^{-1}$ to $4000 \mathrm{~cm}^{-1}$. The following details should be noted during the measurement process: (1) the samples must be kept dry before being measured since moisture absorption from the surrounding air could affect the accuracy of the spectral data; (2) the ATR plate should be cleaned with alcohol and the background spectrum should be re-measured after every scan.

\subsection{Data pre-processing}

It is necessary to use baseline correction (BC) and multivariate scattering correction (MCS) when processing the raw spectral data to obtain better model performance. Specifically, BC is used to linearize the spectrum (Rosén et al., 2010), while MSC is used to eliminate changes in the effective path length between the sample surface and the detector, as well as spectral changes caused by particle size (Geladi and Dbakk, 1999; Geladi et al., 2016). 


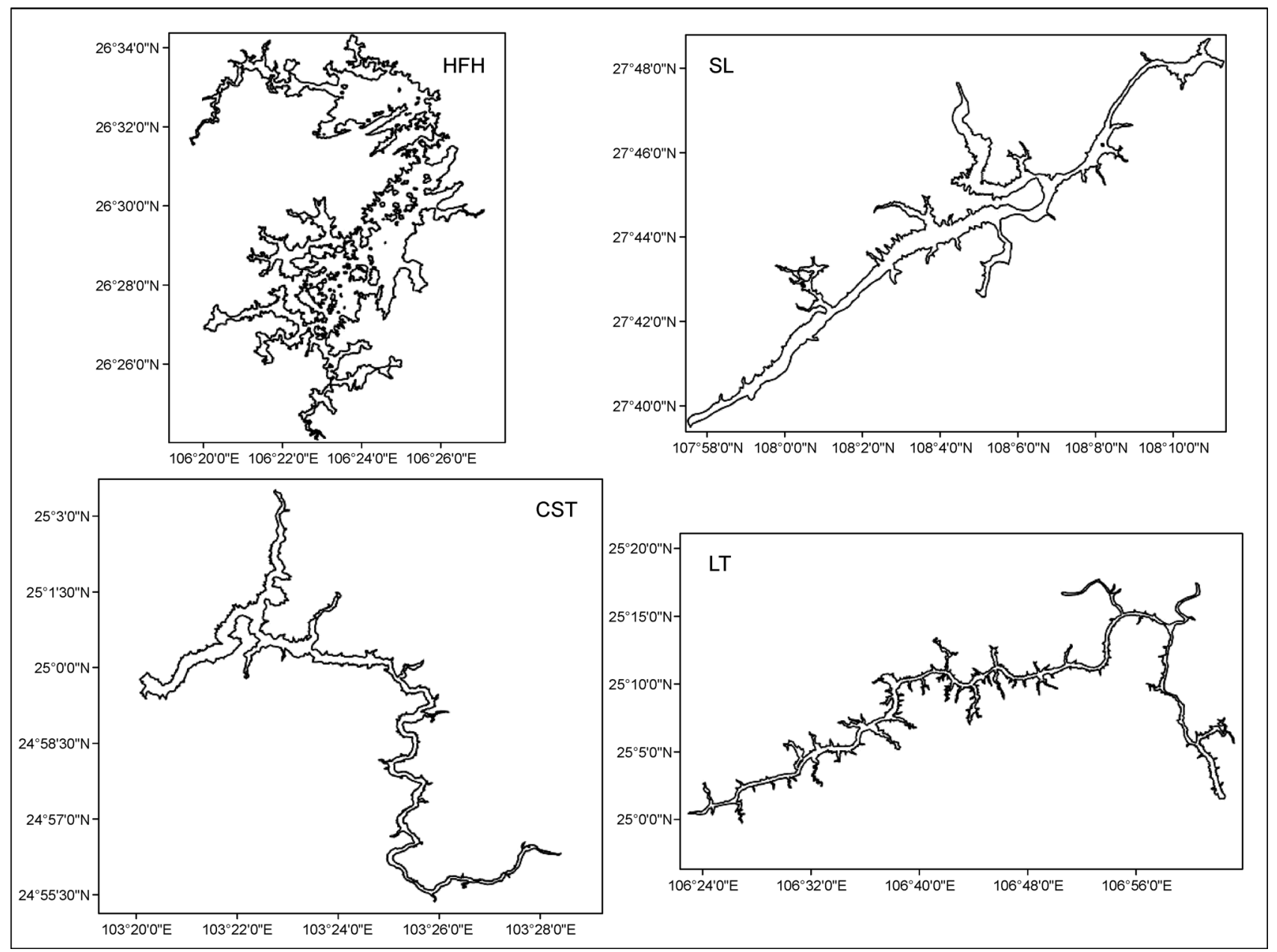

Fig. 1 Map of the study area.

\subsection{Chemometrics analysis}

Sediment samples were divided into either the calibration or validation group. The calibration group contains 91 samples from sediment core 1 of the four reservoirs, which are used to obtain conventional measurements and their corresponding spectral data. This data are then used to create the calibration model for both single and integrated reservoirs. The validation set includes 96 samples from sediment core 2 of the four reservoirs, which are used to assess the accuracy of the calibration model's predictions (Table 1).

The calibration model was developed using partial least squares (PLS) regression. The optimal number of PLS factors was determined by cross-validation (CV) and the minimum factor was obtained by plotting the number of factors against the root mean standard error of cross-validation (RMSECV) (Fig. 2). The fit degree and predictive ability of the calibration model improve as the number of factors increases. However, the predictive ability can only improve to a certain extent, as the complexity of the model reaches a certain level. As a result, it is important to achieve an optimal balance between degree of fit and predictive ability. The optimal number of
Table 1 Basic information of calibration model.

\begin{tabular}{lllll}
\hline Component & Model & $\begin{array}{l}\text { Calibration } \\
\text { set }(n)\end{array}$ & $\begin{array}{l}\text { Validation } \\
\text { set }(n)\end{array}$ & $\begin{array}{l}\text { Factor } \\
(n)\end{array}$ \\
\hline TOC & CST & 34 & 32 & 6 \\
& HFH & 10 & 25 & 5 \\
& LT & 18 & 21 & 7 \\
& SL & 23 & 18 & 6 \\
TN & Integration & 91 & 96 & 9 \\
& CST & 34 & 32 & 4 \\
& HFH & 10 & 25 & 1 \\
& LT & 18 & 21 & 5 \\
& SL & 23 & 18 & 7 \\
& Integration & 91 & 96 & 9
\end{tabular}

Note: TOC, total organic carbon; TN, total nitrogen; CST, Chaishitan reservoir; HFH, Hongfenghu reservoir; LT, Longtan reservoir; SL, Silin reservoir. 


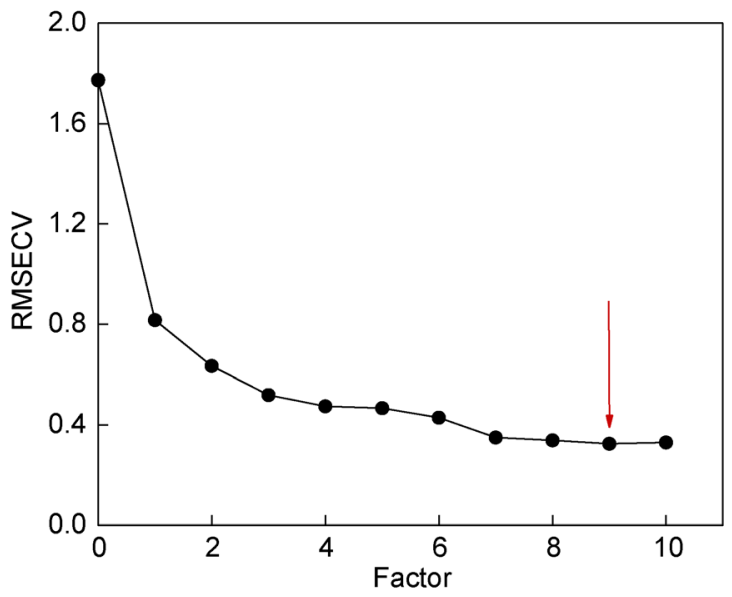

Fig. 2 Root mean square error of cross-validation used to determine the appropriate number of factors to use in the PLS calibration. The point where the model no longer improves with additional factors is marked with an arrow.

factors for each model is shown in Table 1.

The calibration model was tested using the "leave-one-out" cross-validation method (Gurdeniz et al., 2007), which works by building the model with one sample left out and using it to predict the excluded sample. This procedure was repeated until all the samples have been removed and predicted once. After the cross-validation procedure, the correlation coefficients $R_{\mathrm{CV}}^{2}$ and RMSECV values were calculated between the predicted and measured values for all the excluded samples. The resulting high correlation coefficient $R_{\mathrm{CV}}^{2}$ and low
RMSECV value indicate that our model has high robustness and predictive performance.

After the above calibration models were built according to the spectral data of sediment core 2 (validation set), its predicted values were compared to the conventionally measured values to evaluate its accuracy, from which then the correlation coefficient $R^{2}$ and root mean standard error of prediction (RMSEP) values can be calculated. The resulting high $R^{2}$ and low RMSEP values indicate that our model has better prediction accuracy. The TQ Analyst and Origin 2018 software were used for data processing.

\section{Results and discussion}

\subsection{Spectral information}

The spectrograms $\left(500-3750 \mathrm{~cm}^{-1}\right)$ obtained from this study were highly similar to those of marine and lake sediments reported in the literature (Liu et al., 2013; Vogel et al., 2016) (Fig. 3). The four spectrograms demonstrated slight differences as the result of different sediment compositions from different reservoirs. These spectrograms show peaks corresponding to clay, minerals, feldspar, quartz, carbonate, and organic matter. The low intensity peak at $3620 \mathrm{~cm}^{-1}$ corresponds to an $\mathrm{O}-\mathrm{H}$ bond, which indicates the presence of clay minerals (Howe et al., 2002). In addition, the peaks at 3699 and $3620 \mathrm{~cm}^{-1}$ correspond to kaolinite (Kotoky et al., 2006). There is an $\mathrm{O}-\mathrm{H}$ stretching around $3430 \mathrm{~cm}^{-1}$, which may correspond to that of $\mathrm{H}_{2} \mathrm{O}$ molecules or organic matter in the sediment (Veerasingam and Venkatachalapathy, 2014).

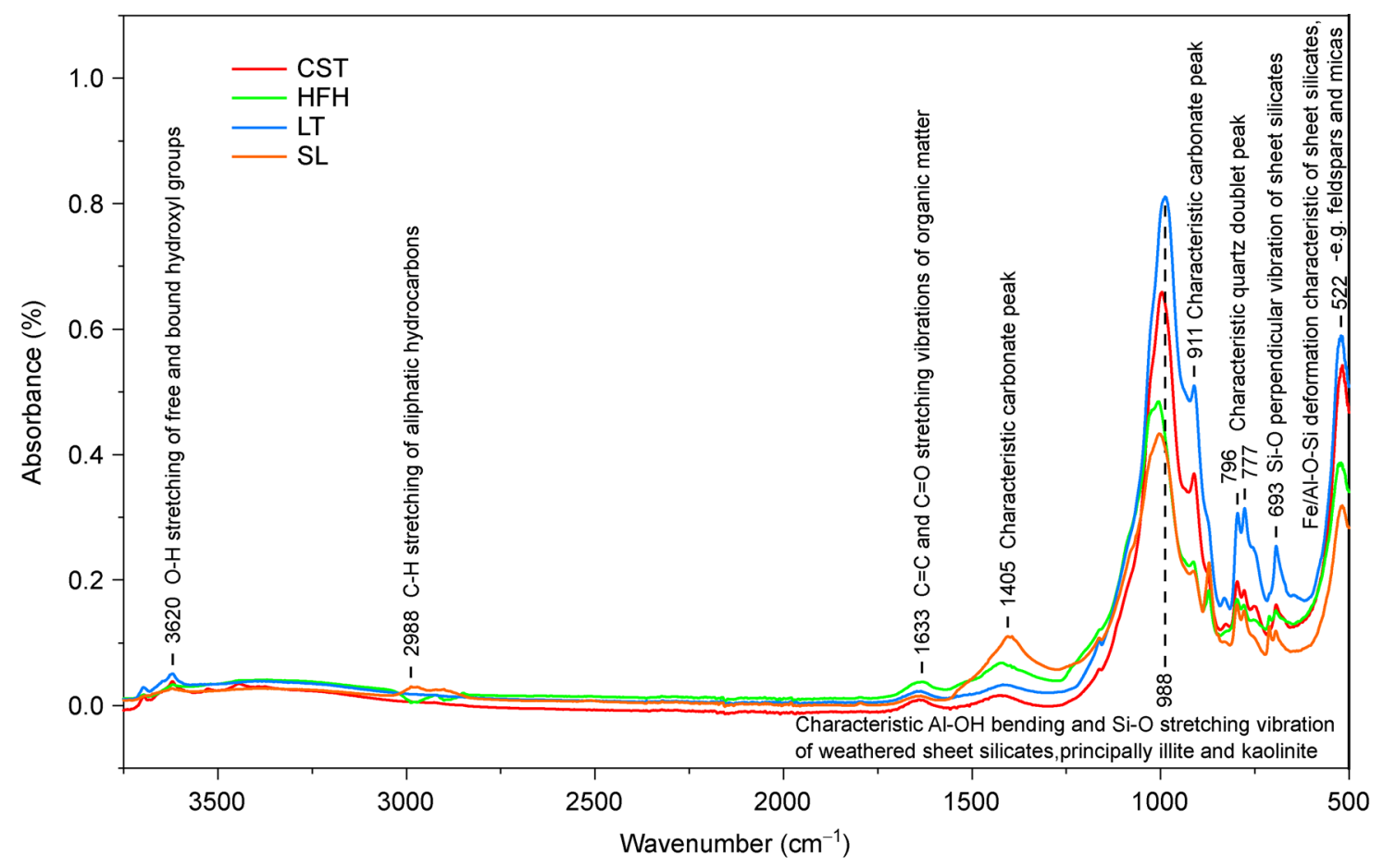

Fig. 3 Infrared spectra of representative sediment samples from four reservoirs. 
The peak at $2988 \mathrm{~cm}^{-1}$ corresponds with a $\mathrm{C}-\mathrm{H}$ bond vibration from aliphatic hydrocarbons. (Oudghiri et al., 2014) and the peak at $1633 \mathrm{~cm}^{-1}$ is caused by a $\mathrm{C}=\mathrm{O}$ (carboxylate group) stretching from organic matter (Matrajt et al., 2004; Langford et al., 2011). The peak at $988 \mathrm{~cm}^{-1}$ may be caused by the characteristic $\mathrm{Si}-\mathrm{O}$ stretching vibration and $\mathrm{Al}-\mathrm{OH}$ bending of weathered lamellar silicates (mainly kaolinite and illite). The peaks at 796,777 , and $693 \mathrm{~cm}^{-1}$ may be due to the presence of quartz minerals (Reig et al., 2002). The $1450 \mathrm{~cm}^{-1}$ peak is caused by the stretching vibration of carbonates, while the $911 \mathrm{~cm}^{-1}$ peak is caused by the bending vibration (Javier et al., 2010).

Generally, organic matter in sediments is composed of different carbon and nitrogen containing functional groups, such as lipids/fatty acids, carbohydrates, proteins, and other biological or geopolymers. The spectral absorption bands at 3400 and $3460 \mathrm{~cm}^{-1}$ are caused by the $\mathrm{O}-\mathrm{H}$ bond vibrations of proteins, carbohydrates, and fatty acids (Kovac et al., 2005). The spectral absorption band at $3010-3030 \mathrm{~cm}^{-1}$ is associated with the $\mathrm{C}-\mathrm{H}$ stretching of $-\mathrm{CH}$ groups on unsaturated hydrocarbon chains, while those at $2850-2950 \mathrm{~cm}^{-1}$ is caused by the $\mathrm{C}-\mathrm{H}$ stretching patterns of $-\mathrm{CH}-\mathrm{CH}_{2}$, and $\mathrm{CH}_{3}$ groups on carbohydrates, proteins, and fatty acid chains (Mecozzi et al., 2009; Rosén et al., 2010). Since the $C=O$ bonds in fatty acids and proteins overlap with the $\mathrm{C}=\mathrm{O}$ bonds in carbonates within the $1500-1700 \mathrm{~cm}^{-1}$ range, the $\mathrm{C}-\mathrm{O}-\mathrm{C}$ vibrations in carbohydrates may produce a peak near 1250 and $1100 \mathrm{~cm}^{-1}$, where $\mathrm{Si}-\mathrm{O}$ bond absorption often occurs (Mecozzi et al., 2009).

Our results show a significant correlation between spectral data and compound content. Previous studies have suggested that it is necessary to select a suitable spectral band to establish a calibration model (Meyer-Jacob et al., 2014). However, there are many overlapping peaks from organic functional groups and relatively broad absorption bands as seen from the above spectrum, which makes it difficult to select and use the spectral data of a specific band to establish a calibration model. The loading plot (Fig. 4) shows the relative contribution of different wavenumbers to the integrated reservoir model of TOC and $\mathrm{TN}$, which demonstrate similar curves. Among them, the $\mathrm{Y}$ variable between 500 and $1500 \mathrm{~cm}^{-1}$ is almost exclusively positive, indicating that the wavenumber of this interval contributes to the establishment of the model. The $Y$ variable between 1500 and $3750 \mathrm{~cm}^{-1}$ is negative and close to zero, indicating that the wavenumber in this interval contributes less to the establishment of the model. Therefore, the region between the $500-1500 \mathrm{~cm}^{-1}$ fingerprint area was selected to establish the calibration model.

\subsection{Calibration model}

The TOC and TN calibration models are shown in Figs. 5 and 6 , respectively. The $R_{\mathrm{CV}}^{2}$ values of the TOC calibration model are 0.90 (CST), $0.93(\mathrm{HFH}), 0.97(\mathrm{LT}), 0.96(\mathrm{SL})$, and 0.97 (Integration), while those of the TN calibration model are 0.87 (CST), 0.75 (HFH), 0.93 (LT), 0.89 (SL), and 0.95 (Integration). The RMSECV values of the TOC calibration model are 0.20 (CST), $0.26(\mathrm{HFH}), 0.08(\mathrm{LT}), 0.12(\mathrm{SL})$, and 0.33 (Integration), and those of the TN calibration model are
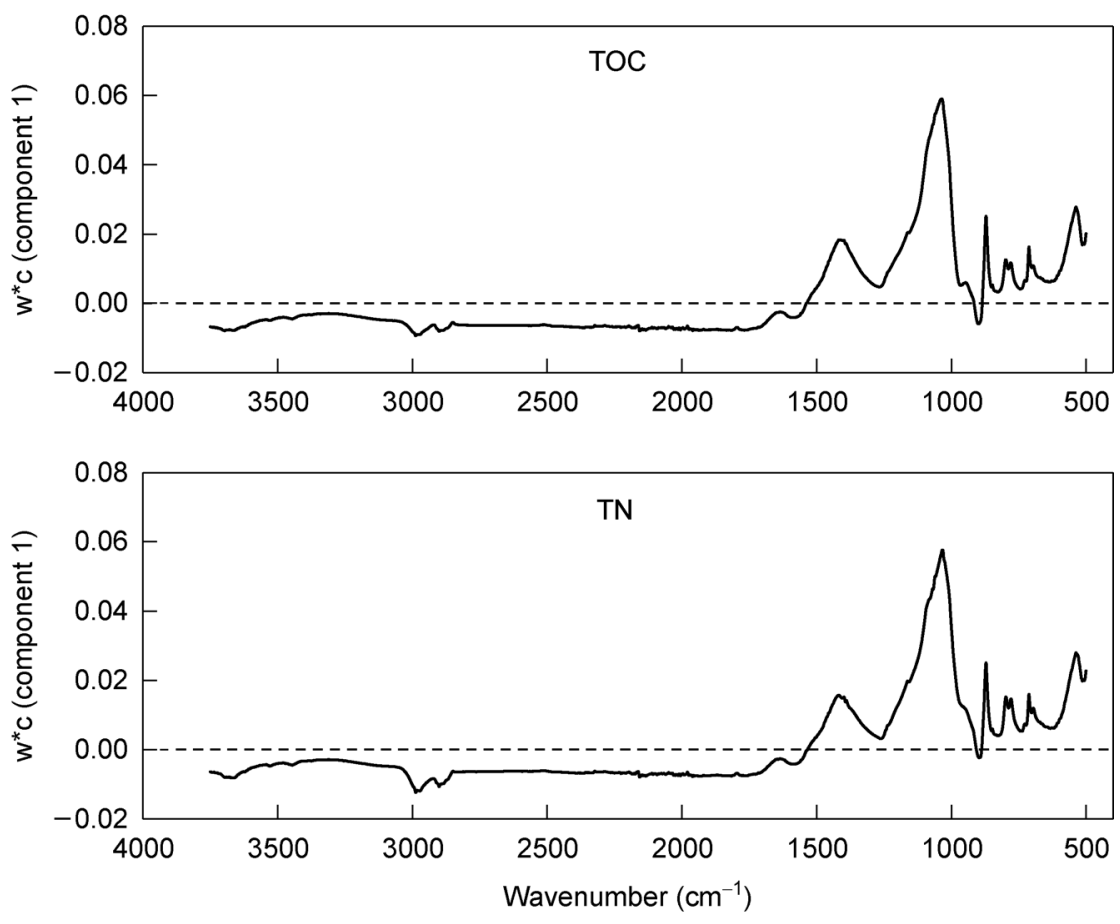

Fig. 4 Loading plots for integration model of TOC and TN. High values indicate wavenumbers are positively correlated to the $Y$ variable and low values indicate wavenumbers are negatively correlated to the $Y$ variable. Loadings refer to the weight vectors $\left(w^{*} \mathrm{c}\right)$ in the calibration model (component 1) ( $y$-axis) and the corresponding spectral region ( $x$-axis). 

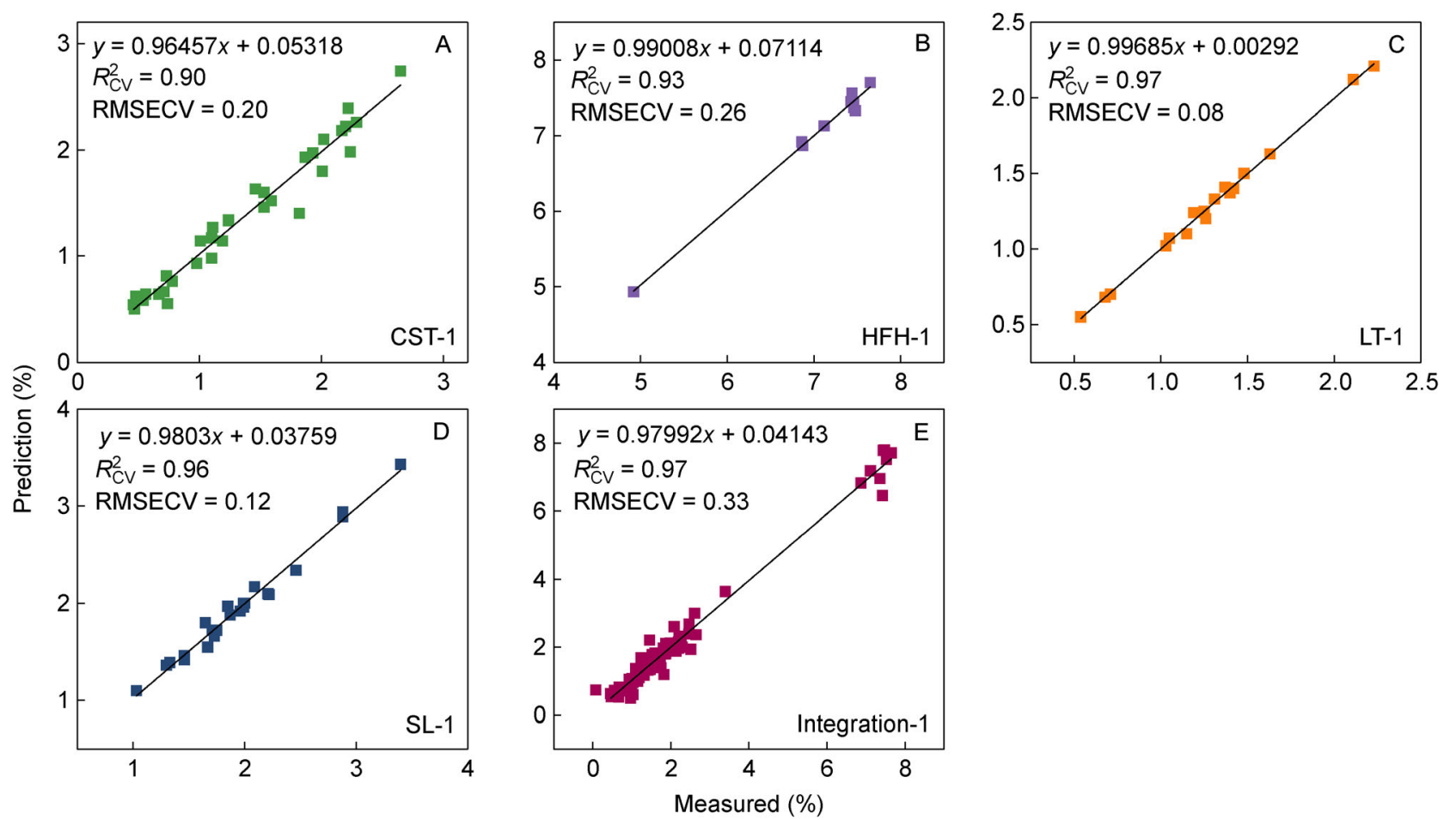

Fig. 5 TOC calibration models. (A-D) Model for single reservoirs. (E) Model for integrated reservoirs.
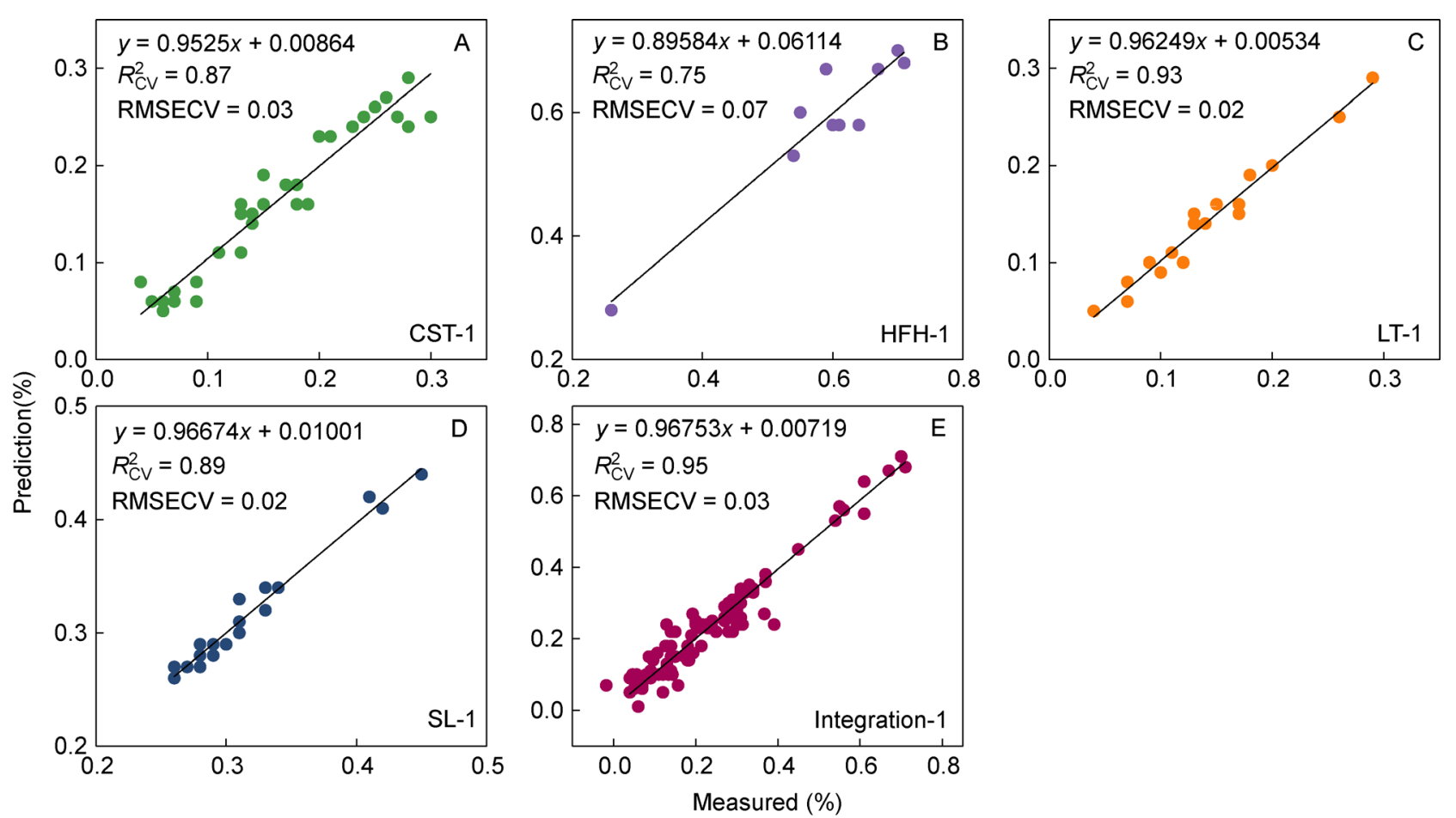

Fig. 6 TN calibration models. (A-D) Model for single reservoirs. (E) Model for integrated reservoirs. 
0.02 (CST), 0.04 (HFH), 0.01 (LT), 0.08 (SL), and 0.03 (Integration).

From the above results, it can be deduced that the TOC calibration model of both single and integrated reservoirs have similar predictive performances. In the case of the TN calibration model, the robustness of the integrated reservoir calibration model is better than that of the single reservoir calibration model.

\subsection{Comparison of predicted and measured values}

A comparison of the results is listed in Fig. 7. All models demonstrated decent prediction performance with a significant correlation between measured and predicted values. The mean $R^{2}$ and RMSEP values of the TOC single reservoir model are 0.85 and 0.68 , respectively, which are both less than the 0.88 and 0.82 values of the integrated reservoir model. The mean $R^{2}$ and RMSEP values of the TN single reservoir model are 0.88 and 0.06 , respectively, which are both less than the 0.90 and 0.07 values of the integrated reservoir model.

The above data indicate that both the single and integrated reservoir models produced reasonable results and showed good prediction performance in practical application.

The vertical sequences of the TOC and TN content in sediment samples were also compared. As seen in Fig. 8, the measured sequences for TOC and TN content of HFH, LT and $\mathrm{SL}$ reservoir sediments were generally consistent with the predicted sequences of each model. In the case of CST, despite an overall similarity of the overall trends, the measured values after $20 \mathrm{~cm}$ differed from the predicted values of the integrated model. One can also see that the TOC and TN content varies between 7 and $17 \mathrm{~cm}$ and increases abruptly after $17 \mathrm{~cm}$. The sediment cores from the CST Reservoir were collected from a sampling site in front of the dam. This specific area was reconstructed at a later stage, which may have interrupted the sedimentary sequence and caused additional materials to accumulate in the reservoir. Field sampling also found that the color of sediments in this section $(7-17 \mathrm{~cm})$ differed from that of other sections, which may be the main reason behind the big difference between our predicted and measured values.

\subsection{Advantages and disadvantages}

The advantage of the FTIR method is that it is highly efficient,
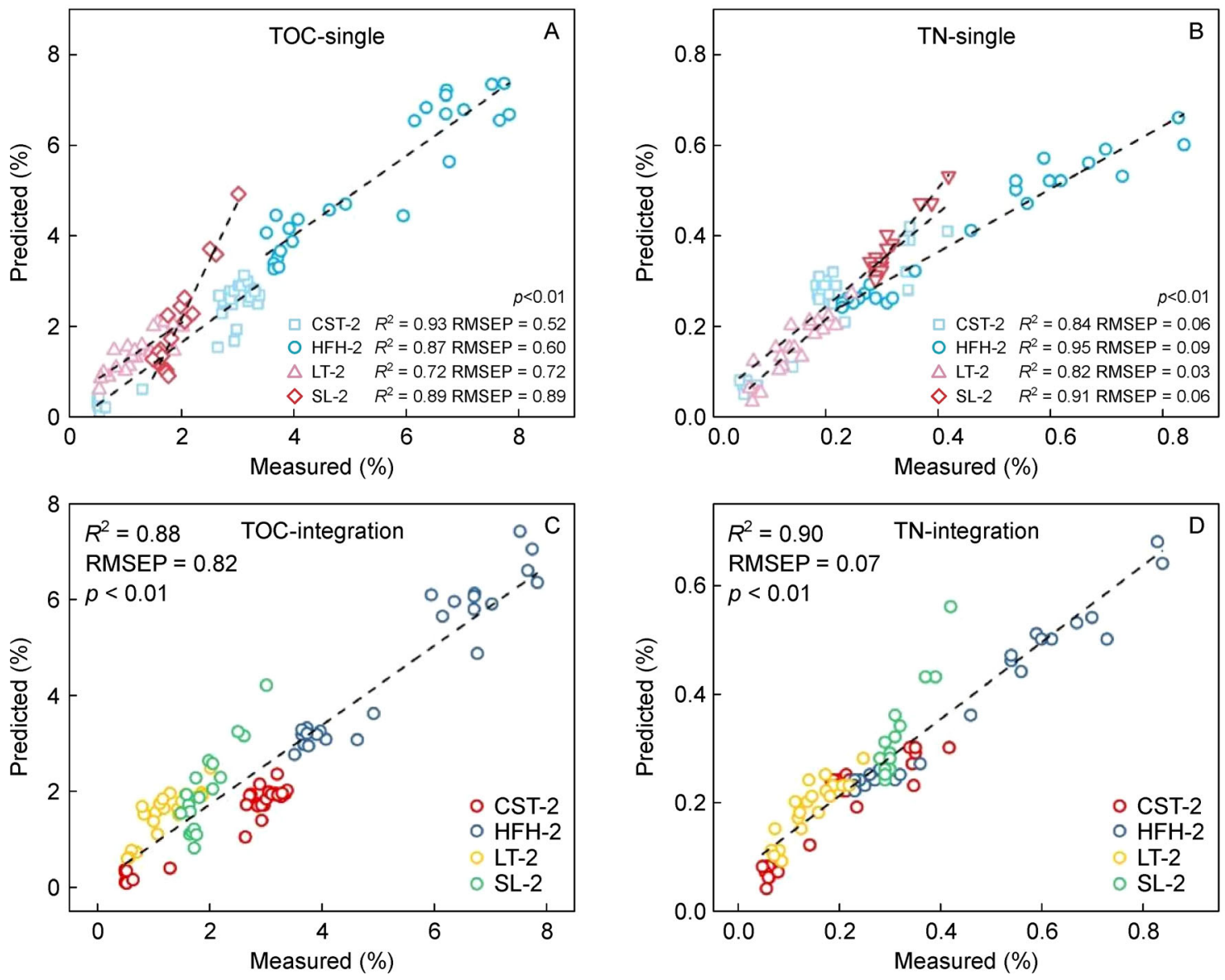

Fig. 7 Comparison of measured values versus predicted values of TOC and TN. (A-B) Model for single reservoirs. (C-D) Model for integrating reservoirs. 


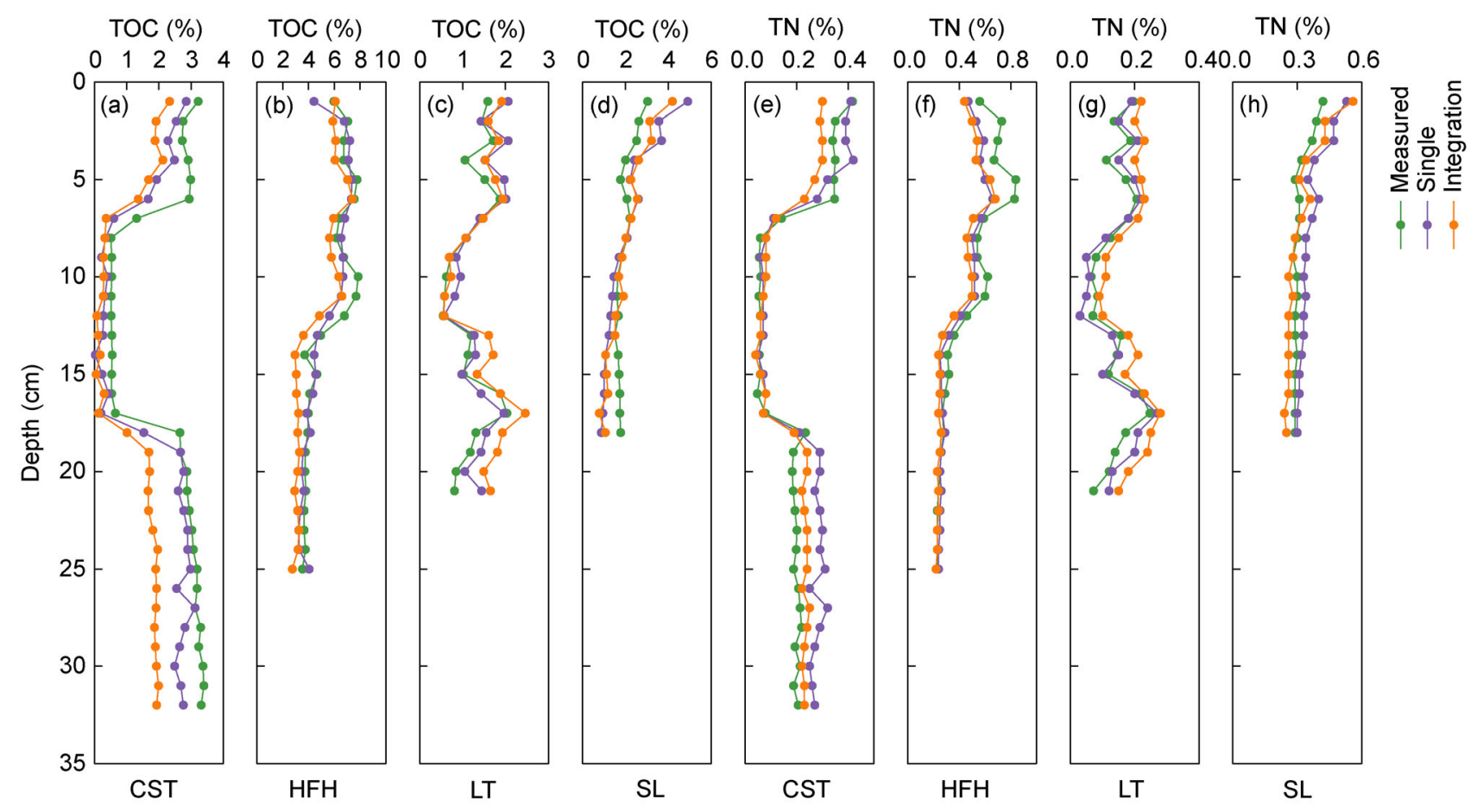

Fig. 8 Variations of TOC and TN content along sediment core.

cost effective, and only require small sample sizes. Its spectra also provide quantitative, biogeochemical information of sediment samples. However, its disadvantage is that different peaks and bands of different compounds may overlap and complicate data interpretation (Liu et al., 2013). Thus, quantitative analyses using FTIR are generally restricted to samples with dominant components or unique absorption bands. In addition, there may be slight differences between traditional and FTIR measurements. Potential causes include sample contamination, differences in sample composition (e.g. grain-size effects), and changes in sample conditions or measurements (Meyer-Jacob et al., 2014).

\section{Conclusion}

This study demonstrates the usefulness and effectiveness of FTIRS as a rapid analytical method for the quantification of TOC and TN in reservoir sediments using small sample quantities $(50 \mathrm{mg})$. This method has its obvious advantages when used to analyze long sediment sequences. The applicability of our developed calibration model significantly reduces the workload required to apply an analytical technique to a new research site or field. Future research should be conducted to investigate the practical applicability of the calibration model in other reservoirs, regions, and geographies. In addition, the development of standard sediment samples would be highly beneficial to improve the prediction accuracy of the model.

\section{Acknowledgments}

This work was supported by the National Key Research and Development Program of China (2016YFA0601003) and Shanghai Science and Technology Development Foundation (19010500100).

\section{References}

Allen, D.T., Palen, E.J., Haimov, M.I., Hering, S.V., Young, J.R., 1994. Fourier transform infrared spectroscopy of aerosol collected in a low pressure impactor (LPI/FTIR): Method development and field calibration. Aerosol Science and Technology 21, 325-342.

Belzile, N., Joly, H.A., Li, H., 1997. Characterization of humic substances extracted from Canadian lake sediments. Canadian Journal of Chemistry 75, 14-27.

Bertaux, J., Ledru, M.P., Soubiès, F., Sondag, F., 1996. The use of quantitative mineralogy linked to palynological studies in palaeoenvironmental reconstruction: the case study of the Lagoa Campestr lake, Salitre, Minas Gerais, Brazil. Comptes rendus académie sciences de Paris Séries II 323:65-71.

Braguglia, C.M., Campanella, L., Petronio, B.M., Scerbo, R., 1995. Sedimentary humic acids in the continental margin of the Ross Sea (ANTARCTICA). International Journal of Environmental Analytical Chemistry 60, 61-70.

Calace, N., Cardellicchio, N., Petronio, B.M., Pietrantonio, M., Pietroletti, M., 2006. Sedimentary humic substances in the northern Adriatic sea (Mediterranean sea). Marine Environmental 
Research 61, 40-58.

Che Man, Y.B., Syahariza, Z.A., Mirghani, M.E.S., Jinap, S., Bakar, J., 2005. Analysis of potential lard adulteration in chocolate and chocolate products using Fourier transform infrared spectroscopy. Food Chemistry 90, 815-819.

Cohen, A., Soreghan, M., Scholtz, C., 1993. Estimating the age of formation of lakes: An example from Lake Tanganyika East African Rift system. Geology 21, 511-514.

Colman, S.M., Peck, J.A., Karabanov, E.B., Carter, S.J., Bradbury, J. P., King, J.W., Williams, D.F., 1995. Continental climate response to orbital forcing from biogenic silica records in Lake Baikal. Nature 378, 769-771.

Coury, C., Dillner, A.M., 2008. A method to quantify organic functional groups and inorganic compounds in ambient aerosols using attenuated total reflectance FTIR spectroscopy and multivariate chemometric techniques. Atmospheric Environment 42, 5923 5932.

Fuji, N., 1998. Palaeovegetation and palaeoclimate changes around Lake Biwa, Japan during the last CA. 3 million years. Quaternary ence Reviews 7, 21-28.

Geladi, P., Dbakk, E., 1999. Computational Methods and Chemometrics in Near Infrared Spectroscopy. Encyclopedia of Spectroscopy and Spectrometry (2nd ed). pp. 386-391.

Geladi, P., Macdougall, D., Martens, H., 2016. Linearization and scatter-correction for near-infrared reflectance spectra of meat. Applied Spectroscopy 39, 491-500.

Gurdeniz, G., Tokatli, F., Ozen, B., 2007. Differentiation of mixtures of monovarietal olive oils by mid-infrared spectroscopy and chemometrics. European Journal of Lipid Science and Technology 109 1194-1202.

Howe, K.J., Ishida, K.P., Clark, M.M., 2002. Use of ATR/FTIR spectrometry to study fouling of microfiltration membranes by natural waters. Desalination 147, 251-255.

Javier, M., Cassellab, R.J., C.Barciela-Alonsoc, M., Moreda-Piñeiroc, A., Herbello-Hermeloc, P., Bermejo-Barrerac, P., Garriguesa, S., de la Guardiaa, M., 2010. Estuarine sediment quality assessment by Fourier-transform infrared spectroscopy. Vibrational Spectroscopy 53, 204-213.

Kotoky, P., Bezbaruah, D., Baruah, J., Borah, G.C., Sarma, J.N., 2006. Characterization of clay minerals in the Brahmaputra river sediments, Assam, India. Current Science 91, 1247-1250.

Kovac, N., Faganeli, J., Bajt, O., Orel, B., Vuk, A., 2005. Investigation of sediment samples from the Gulf of Trieste (northern Adriatic) by FTIR spectroscopy. Mater Geoenvi 52, 81-85.

Langford, H., Hodson, A., Banwart, S., 2011. Using FTIR spectroscopy to characterise the soil mineralogy and geochemistry of cryoconite from Aldegondabreen glacier, Svalbard. Applied Geochemistry 26, S206-S209.

Liu, X., Colman, S.M., Brown, E.T., Minor, E.C., Li, H., 2013. Estimation of carbonate, total organic carbon, and biogenic silica content by FTIR and XRF techniques in lacustrine sediments Journal of Paleolimnology 50, 387-398.

Matrajt, G., Borg, J., Raynal, P.I., Djouadi, Z.D., Hendecourt, L., Flynn, G., Deboffle, D., 2004. FTIR and Raman analyses of the Tagish Lake meteorite: Relationship with the aliphatic hydrocarbons observed in the Diffuse Interstellar Medium. Astronomy \&
Astrophysics 416, 549-554.

Mecozzi, M., Pietrantonio, E., Amici, M., Romanelli, G., 2001. Determination of carbonate in marine solid samples by FTIRATR spectroscopy. Analyst (London) 126, 144-146.

Mecozzi, M., Pietrantonio, E., Pietroletti, M., 2009. The roles of carbohydrates, proteins and lipids in the process of aggregation of natural marine organic matter investigated by means of $2 \mathrm{D}$ correlation spectroscopy applied to infrared spectra. Spectrochimica Acta. Part A: Molecular and Biomolecular Spectroscopy 71, 1877-1884.

Meyer-Jacob, C., Vogel, H., Gebhardt, A.C., Wennrich, V., Melles, M., Rosen, P., 2014. Biogeochemical variability during the past 3.6 million years recorded by FTIR spectroscopy in the sediment record of Lake El'gygytgyn, Far East Russian Arctic. Climate of the Past 10, 209-220.

Oudghiri, F., Garcia-Morales, J.L., Rodriguez-Barroso, M.R., 2014. Rapid Screening of Estuarine Sediments Properties Using Thermogravimetric Analysis and Attenuated Total Reflectance (ATR) by Fourier Transform Infrared (FTIR) Spectrometry. Water Air and Soil Pollution 225, 1853.1-1853.10.

Peck, J.A., King, J.W., Colman, S.M., Kravchinsky, V.A., 1994. A rockmagnetic record from Lake Baikal, Siberia: Evidence for Late Quaternary climate change. Earth and Planetary Science Letters 122, 0-238.

Reig, F.B., Adelantado, J.V.G., Moreno, M.C.M.M., 2002. FTIR quantitative analysis of calcium carbonate (calcite) and silica (quartz) mixtures using the constant ratio method. Application to geological samples. Talanta 58, 811-821.

Rosén, P., Persson, P., 2006. Fourier-transform Infrared Spectroscopy (FTIRS), a new method to infer past changes in tree-line position and TOC using lake sediment. Journal of Paleolimnology 35, 913-923.

Rosén, P., Vogel, H., Cunningham, L., Reuss, N., Conley, D.J., Persson, P., 2010. Fourier transform infrared spectroscopy, a new method for rapid determination of total organic and inorganic carbon and biogenic silica concentration in lake sediments. Journal of Paleolimnology 43, 247-259.

Sifeddine, A., 1994. The lacustrine organic sedimentation in tropical humid environment (Carajas, eastern Amazonia, Brazil): relationship with climatic changes during the last 60000 years B.P. Bulletin de la Société Géologique de France 165, 613-621.

Tiercelin, J.J.,Lezzar, K.E., 2004. A 300 Million Years History of Rift Lakes in Central and East Africa: An Updated Broad Review. In: Odada, E.O., Olago, D.O. (eds.) The East African Great Lakes: Limnology, Palaeolimnology and Biodiversity. Advances in Global Change Research, vol 12. Springer, Dordrecht. https://doi.org/ 10.1007/0-306-48201-0_1.

Veerasingam, S., Venkatachalapathy, R., 2014. Estimation of carbonate concentration and characterization of marine sediments by Fourier Transform Infrared Spectroscopy. Infrared Physics \& Technology 66, 136-140.

Vogel, H., Meyer-Jacob, C., Thöle, L., Lippold, J.A., Jaccard, S.L., 2016. Quantification of biogenic silica by means of Fourier transform infrared spectroscopy (FTIRS) in marine sediments. Limnology and Oceanography, Methods 14, 828-838.

Vogel, H., Rosén, P., Wagner, B., Melles, M., Persson, P., 2008. 
Fourier transform infrared spectroscopy, a new cost-effective tool for quantitative analysis of biogeochemical properties in long sediment records. Journal of Paleolimnology 40, 689-702.

Williams, D., Peck, J.A., Karabanov, E., Prokopenko, A., 1997. Lake

Baikal record of continental climate response to orbital insolation during the past 5 million years. Science 278, 1114-1117.

Wirmann, D., Bertaux, J., Kossoni, A., 2001. Late holocene paleoclimatic changes in Western Central Africa inferred from mineral abundance in dated sediments from Lake Ossa (Southwest Cameroon). Quaternary Research 56, 275-287. 